\title{
Evaluation System Modeling of Information Disclosure of Sports Organization Websites Using Analytic Hierarchy Process
}

\author{
Yanqin Su \\ Faculty of Physical Education, Chengdu University, Chengdu, Sichuan, China \\ yanqinsu@foxmail.com
}

Keywords: evaluation system; website; analytic hierarchy process; information disclosure; sports organization.

\begin{abstract}
In this study, the author explored information disclosure of sports organization websites in China using analytic hierarchy process. After analyzing the existing and collected data, this research came into the following conclusions: (a) the degree of information disclosure in provincial sports organization was somewhat lower in China, (b) there is positive correlation between service ability and the degree of information disclosure, and (c) the economic power have an important role on information disclosure. The author gives some proposals on improving regulatory mechanism of information disclosure, organization construction, information technology, and strengthening publicity.
\end{abstract}

\section{Introduction}

The analytic hierarchy process is a structured technique for organizing and analyzing complex decisions, based on mathematics and psychology. It was developed byThomas L. Saaty in the 1970s and has been extensively studied and refined since then.It has particular application in group decision making, and is used around the world in a wide variety of decision situations, in fields such as government, business, industry, healthcare, and education. In this study, the author explored the information disclosure in sports websites using analytic hierarchy process.

In the recent literature, many researchers have done vary researches on information disclosure. For example, Gordon et al. assessed empirically the market value of voluntary disclosures of items pertaining to information security [1]. Heirman et al.adopted a global theoretical framework to predict adolescents' disclosure of personal information in exchange for incentives offered by commercial Websites. The authors postulated and tested the validity of a model based on the theory of planned behavior, including antecedent factors of attitude and perceived behavioral control [2]. Zhang provided a theoretical model to examine the economic incentives behind these two forms of information dissemination and their consequences on the cost of capital [3]. Lang et al.examined corporate disclosure activity around seasoned equity offerings and its relationship to stock prices [4]. Kumar et al.examined the valuation and capital allocation roles of voluntary disclosure when managers have private information regarding the firm's investment opportunities [5]. Medjoudj et al. investigated the customer satisfaction of power users using the Analytic Hierarchy Process method [6]. Sharma et al. developed a risk management framework for project risk management in construction projects and demonstrate its application in an ongoing construction project [7]. Cannavacciuolo et al. presented a model based on activity based costing and analytic hierarchy process to assess the impact of individual competencies on value creation and its application to a case study of a small manufacturing firm[8].Mikhailo et al. dealt with the group prioritization problem in the fuzzy analytic hierarchy process[9]. 


\section{Modeling}

\subsection{Index selection}

According to the requirements of the research using analytic hierarchy process, this study divided the problem into different levels, and according to interrelated factors and affiliations relation between different levels, this study form a multi-level analysis model. This model listed in table 1.

Table 1. Layer model of evaluation system of information disclosure of sports organization websites

\begin{tabular}{|c|c|c|}
\hline Target layer: A & Guidelines layer: B & Index layer: C \\
\hline \multirow{4}{*}{$\begin{array}{c}\text { Evaluation system of } \\
\text { information disclosure } \\
\text { of sports organization websites }\end{array}$} & Contents: B1 & Fund resource : C1 \\
\cline { 2 - 3 } & Organization and management: B2 & Role and effect : C2 \\
\cline { 2 - 3 } & & Registration information: C3 \\
\cline { 2 - 3 } & \multirow{3}{*}{ Busic infrastructure: B3 } & Personnel information : C5 \\
\cline { 2 - 3 } & & Website construction : C6 \\
\cline { 2 - 3 } & & Infrastructure status: C7 \\
\cline { 2 - 3 } & & Amount of membership : C8 \\
\hline
\end{tabular}

Table 2. General information on official website of province-level sports organization in China

\begin{tabular}{|c|c|c|c|}
\hline Province & Total & $\begin{array}{c}\text { With official websites } \\
(\%)\end{array}$ & $\begin{array}{l}\text { Without official websites } \\
(\%)\end{array}$ \\
\hline 1. Shanghai & 73 & 19.2 & 80.8 \\
\hline 2. Beijing & 72 & 31.9 & 68.1 \\
\hline 3. Jiangsu & 50 & 24.0 & 76.0 \\
\hline 4. Shandong & 46 & 21.7 & 78.2 \\
\hline 5. Zhejiang & 46 & 15.2 & 84.8 \\
\hline 6. Fujian & 43 & 11.6 & 88.4 \\
\hline 7. Xinjiang & 40 & 22.5 & 77.5 \\
\hline 8. Qinghai & 39 & 7.7 & 92.3 \\
\hline 9. Gansu & 36 & 8.3 & 91.7 \\
\hline 10. Shanxi & 30 & 13.3 & 86.7 \\
\hline 11.Guizhou & 26 & 3.8 & 96.2 \\
\hline 12.Hebei & 23 & 34.8 & 65.2 \\
\hline 13.Hubei & 23 & 4.3 & 95.7 \\
\hline 14.Hunan & 22 & 18.2 & 81.8 \\
\hline 15.Henan & 21 & 47.6 & 52.4 \\
\hline 16.Tianjin & 18 & 27.8 & 72.2 \\
\hline 17.Ningxia & 17 & 5.9 & 94.1 \\
\hline 18.Jilin & 14 & 28.6 & 71.4 \\
\hline 19.Shanxi & 14 & 21.4 & 78.6 \\
\hline 20.Hainan & 13 & 30.8 & 69.2 \\
\hline 21.Yunnan & 13 & 15.4 & 84.6 \\
\hline 22.Jiangxi & 10 & 20.0 & 80.0 \\
\hline 23.Chongqing & 8 & 50.0 & 50.0 \\
\hline
\end{tabular}

Note: the sports organization in other province not listed above are null.

\subsection{Mathematic Modeling for information disclosure}

The goal score of first level assessment formula is as follows:

$G=\sum F_{i} W_{i}$

Where 
$\mathrm{G}$ is the goal score, $\mathrm{F}$ is the score of first level indexes, $\mathrm{W}$ is the weighted value of each index, and $i$ is the $i$-th item index in first level index

The second level assessment formula is as follows

$F_{i}=\sum S_{i j} W_{i j}$

Where

$\mathrm{F}$ is the score of first level indexes, $\mathrm{S}$ is the score of first level indexes, $\mathrm{W}$ is the weighted value of each index, and $\mathrm{j}$ is the $\mathrm{j}$-th item index in second level index

\section{Results}

The survey objects in this study involved 697 province-level sports organization in 31 provinces in China. By means of researching for websites of provincial administration of sport and sports federation and analyzing them, we came into some conclusion on the information disclosure status, the general information on official website of province-level sports organization in China was listed in table 2.

By means of analysis, the results indicated that the weight of contents, organization and management, and basic infrastructure are $0.4172,0.2947$, and 0.2881 , respectively. The weight of fund resource, role and effect, registration information, rules and regulations, personnel information, website construction, infrastructure status, and amount of membership are $0.17376,0.14344,0.18735$, $0.1486,0.0486,0.0668,0.12202$, and 0.11002 respectively.

Table 3. Classification statistics on goal score for province-level sports organization in possess of official website

\begin{tabular}{|c|c|}
\hline Goal score & Percent (\%) \\
\hline Above 60 & 38.7 \\
\hline Between 45 and 60 & 19.4 \\
\hline Less than 45 & 16.1 \\
\hline Absent data & 25.8 \\
\hline Total & 100 \\
\hline
\end{tabular}

With the equation 1 and 2, this study obtained the goal scores of province-level sports organization, the highest goal scores are Beijing, Shanghai and Zhejiang, they are 76.2, 72.4, and 67.8 respectively. The classification statistics on region for province-level sports organization of scores distribution are listed in table 3.

\section{Conclusion}

From the results mentioned above, the conclusion cane into as follows: (a) the degree of information disclosure in provincial sports organization was somewhat lower in China, (b) there is positive correlation between service ability and the degree of information disclosure, (c)the economical power have an important role on information disclosure, and (d) for the shortcomings of information disclosure in province-level sports organization, we should improve regulatory mechanism of information disclosure, organization construction, information technology, and strengthen publicity, in doing so to enhance the service capabilities of province-level sports organizations .

\section{References}

[1] Gordon, Lawrence A.; Loeb, Martin P.; Sohail, Tashfeen. Market Value of Voluntary Disclosures Concerning Information Security. MIS Quarterly. Sep2010, Vol. 34 Issue 3, p567-A2.

[2] Heirman, Wannes; Walrave, Michel; Ponnet, Koen. CyberPsychology, Predicting Adolescents' Disclosure of Personal Information in Exchange for Commercial Incentives: An Application of an 
Extended Theory of Planned Behavior. Behavior \& Social Networking. Feb 2013, Vol. 16 Issue 2, p81-87

[3] Zhang, Guochang.Private Information Production, Public Disclosure, and the Cost of Capital: Theory and Implications.Contemporary Accounting Research. Summer2001, Vol. 18 Issue 2, p363-384.

[4] Lang, Mark H.; Lundholm, Russell J.Voluntary Disclosure and Equity Offerings: Reducing Information Asymmetry or Hyping the Stock Contemporary Accounting Research. Winter2000, Vol. 17 Issue 4, p623-662.

[5] Kumar, Praveen; Langberg0, Nisan; Sivaramarkrishnan, K. Voluntary Disclosures, Corporate Control, and Investment. Journal of Accounting Research. Sep2012, Vol. 50 Issue 4, p1041-1076.

[6] Medjoudj, R.; Laifa, A.; Aissani, D.Decision making on power customer satisfaction and enterprise profitability analysis using the Analytic Hierarchy Process. International Journal of Production Research. Sep 2012, Vol. 50 Issue 17, p4793-4805.

[7] Sharma, Satyendra Kumar.Risk Management in Construction Projects Using Combined Analytic Hierarchy Process and Risk Map Framework.IUP Journal of Operations Management. Nov2013, Vol. 12 Issue 4, p23-53.

[8] Cannavacciuolo, Lorella; Iandoli, Luca; Ponsiglione, Cristina; Zollo, Giuseppe. An analytical framework based on AHP and activity-based costing to assess the value of competencies in production processes. International Journal of Production Research. Sep2012, Vol. 50 Issue 17, p4877-4888.

[9] Mikhailov, Ludmil; Didehkhani, Hosein; Sadi-nezhad, Soheil.Weighted Prioritization Models in the Fuzzy Analytic Hierarchy Process. International Journal of Information Technology \& Decision Making. Jul2011, Vol. 10 Issue 4, p681-694. 